\title{
Comparison of purple carrot juice and $\beta$-carotene in a high-carbohydrate, high-fat diet-fed rat model of the metabolic syndrome
}

\author{
Hemant Poudyal ${ }^{1}$, Sunil Panchal ${ }^{1,2}$ and Lindsay Brown ${ }^{1,2} *$ \\ ${ }^{1}$ School of Biomedical Sciences, The University of Queensland, Brisbane, QLD 4072, Australia \\ ${ }^{2}$ Department of Biological and Physical Sciences, University of Southern Queensland, Toowoomba, QLD 4350, Australia
}

(Received 7 January 2010 - Revised 5 May 2010 - Accepted 10 May 2010 - First published online 12 July 2010)

Anthocyanins, phenolic acids and carotenoids are the predominant phytochemicals present in purple carrots. These phytochemicals could be useful in treatment of the metabolic syndrome since anthocyanins improve dyslipidaemia, glucose tolerance, hypertension and insulin resistance; the phenolic acids may also protect against CVD and $\beta$-carotene may protect against oxidative processes. In the present study, we have compared the ability of purple carrot juice and $\beta$-carotene to reverse the structural and functional changes in rats fed a high-carbohydrate, high-fat diet as a model of the metabolic syndrome induced by diet. Cardiac structure and function were defined by histology, echocardiography and in isolated hearts and blood vessels; liver structure and function, oxidative stress and inflammation were defined by histology and plasma markers. High-carbohydrate, high-fat diet-fed rats developed hypertension, cardiac fibrosis, increased cardiac stiffness, endothelial dysfunction, impaired glucose tolerance, increased abdominal fat deposition, altered plasma lipid profile, liver fibrosis and increased plasma liver enzymes together with increased plasma markers of oxidative stress and inflammation as well as increased inflammatory cell infiltration. Purple carrot juice attenuated or reversed all changes while $\beta$-carotene did not reduce oxidative stress, cardiac stiffness or hepatic fat deposition. As the juice itself contained low concentrations of carotenoids, it is likely that the anthocyanins are responsible for the antioxidant and anti-inflammatory properties of purple carrot juice to improve glucose tolerance as well as cardiovascular and hepatic structure and function.

Purple carrots: Anthocyanins: $\beta$-Carotene: Metabolic syndrome: High-carbohydrate, high-fat diet-fed rats

Diet plays an important role in the aetiology and prevention of the risk factors of the metabolic syndrome ${ }^{(1)}$. Many epidemiological studies have shown a strong inverse association between an increased consumption of fruits and vegetables and a decreased incidence of $\mathrm{CVD}^{(2-5)}$, especially stroke $^{(3)}$, $\mathrm{IHD}^{(2,3)}, \mathrm{CHD}^{(4)}$ and blood pressure ${ }^{(5)}$. Although the risk of type 2 diabetes is not related to the consumption of fruit or vegetables, the intake of antioxidant phytochemicals has been associated with reduction in the risk of type 2 diabetes ${ }^{(6,7)}$. Close relationships between obesity, the metabolic syndrome and the development of non-alcoholic fatty liver disease (NAFLD) have been described, with most NAFLD patients displaying multiple components of the metabolic syndrome ${ }^{(8)}$. However, the effects of increased intakes of fruit and vegetables on NAFLD patients have not been studied.

Glucosinolates, flavonoids, tannins, carotenoids, phytates and phyto-oestrogens represent the major classes of phytochemicals present in fruits and vegetables ${ }^{(9)}$. These nutrients may improve health through many mechanisms, such as reducing oxidative stress and inflammation, improving lipid profiles, lowering blood pressure and enhancing glucose metabolism $^{(9)}$. Anthocyanins, a subclass of flavonoids, are pigments of red fruits such as cherries, plums, strawberries, raspberries, blackberries, grapes, red and black currants and, together with the phenolic acids, are the major phytochemicals in the human diet ${ }^{(10)}$. Although research on the therapeutic uses of the phytochemicals in carrots started with the demonstration of pro-vitamin A activity by Moore in $1929^{(11)}$, few data exist on possible therapeutic benefits from carrot varieties other than orange carrots where $\beta$-carotene is the predominant phytochemical component.

Carrot varieties differ in colour from white to orange, yellow, red and purple and contain different combinations and quantities of macronutrients, fibre, vitamins, minerals and phytochemicals including carotenoids, phenolic acids, anthocyanins, isocoumarins, terpenes and sesquiterpenes ${ }^{(12,13)}$. The colour of orange carrots is due to higher concentrations of $\alpha$ - and $\beta$-carotene; red carrots contain increased lycopene and yellow carrots contain increased lutein concentrations while white carrots have lower concentrations of all carotenoids ${ }^{(13)}$. The anthocyanidins and chlorogenic acid are the major antioxidants in purple carrots ${ }^{(13,14)}$. The colour of purple carrots (Daucus carota L. ssp. sativus var. atrorubens Alef.) comes from the presence of

Abbreviations: CRP, C-reactive protein; H (8 weeks or 16 weeks), high-carbohydrate, high-fat; HC, high-carbohydrate, high-fat $+\beta$-carotene; HP, high-

carbohydrate, high-fat + purple carrot juice; NAFLD, non-alcoholic fatty liver disease.

* Corresponding author: Professor Lindsay Brown, fax +61 74631 1530, email Lindsay.Brown@usq.edu.au 
anthocyanins such as cyanidin-3-(2 $2^{\prime \prime}$-xylose- $6^{\prime \prime}$-sinapoylglucose-galactoside $)^{(13,15)}$. Additionally, at least forty phenolic acids are present in purple carrots including chlorogenic and caffeic acids as the predominant compounds ${ }^{(13)}$. Purple carrots also contain polyacetylene compounds such as falcarindiol, falcarindiol 3-acetate and falcarinol ${ }^{(16)}$. Purple carrots remain a sparsely studied potential dietary component that are rich in anthocyanins, phenolic acids and carotenoids ${ }^{(13)}$.

$\beta$-Carotene, the best known of the large carotenoid family of phytochemicals, is the major dietary source of vitamin A (retinol). Epidemiological studies have inversely associated circulating $\beta$-carotene concentrations with the risk of hypertension $^{(17,18)}$ but not with type 2 diabetes $^{(19,20)}$. The antioxidant as well as pro-oxidant actions of $\beta$-carotene are widely known ${ }^{(21,22)}$. Carotenoids, particularly $\beta$-carotene and lycopene, protect animals and humans against oxidative processes, especially in lipophilic environments such as cell membranes by acting as free radical scavengers ${ }^{(23)}$. Carotenoids have been proposed as a dietary strategy to prevent cancers, possibly by antioxidant actions and the stimulation of intercellular communication via gap junctions ${ }^{(23)}$. In vivo, $\beta$-carotene prevented ethanol-induced liver damage and improved hepatic antioxidant enzyme status in rats $^{(24)}$. In streptozotocin-induced diabetic rats, $\beta$-carotene treatment increased hepatic and cardiac antioxidant enzymes ${ }^{(25)}$, improved circulatory insulin and glucose concentrations $^{(26)}$ but increased lipid peroxidation ${ }^{(25)}$.

Epidemiological studies have shown that plant-based diets protect against CVD and cancer; flavonoids, including the anthocyanins, occur widely in plants and may improve human health ${ }^{(27,28)}$. In particular, the anthocyanins may improve the symptoms of the metabolic syndrome such as dyslipidaemia, impaired glucose tolerance and hypertension $^{(27,28)}$. Anthocyanin-rich plant extracts lowered plasma lipid concentrations in rat models of hyperlipidaemia $^{(29,30)}$ and an extract from black rice (Oryza sativa L. indica) lowered plasma lipid concentrations and improved insulin resistance in fructose-fed rats $^{(31)}$. Spontaneously hypertensive rats fed on anthocyanin-rich purple maize, purple sweet potato and red radish showed reduced blood pressure and heart rate ${ }^{(32)}$. Other constituents of carrots such as the polyacetylenes may suppress inflammation in the metabolic syndrome by decreasing lipopolysaccharideinduced expression of inflammatory proteins in macrophages and endothelial cells ${ }^{(12)}$.

Although the phytochemical profile of purple carrots has been reported, sparse information exists on the pharmacological activity of purple carrot juice. The aims of the present study were to determine whether purple carrot juice attenuates or reverses the cardiovascular, liver and metabolic changes produced in a high-carbohydrate, high-fat diet-fed rat model of the metabolic syndrome and whether these responses are comparable with that of $\beta$-carotene.

Diets with increased carbohydrates, mainly as fructose ${ }^{(33)}$, increased fats ${ }^{(34)}$ or a combination of both ${ }^{(35)}$ in rats have been studied to mimic the human metabolic syndrome. Maize starch is a slowly digestible carbohydrate ${ }^{(36)}$ and served as a control for the high-carbohydrate, high-fat diet in the present study where the primary carbohydrate is fructose. Unlike fructose, maize starch does not increase blood glucose, plasma insulin or NEFA concentrations ${ }^{(35,36)}$.
The present study characterised structural changes in the rat heart by histology and echocardiography, while heart function was assessed in vivo using echocardiography and ex vivo in isolated perfused hearts. Systolic blood pressure was measured and isolated thoracic rings were used to measure vascular reactivity. Biochemical parameters (enzyme activities of alanine transaminase, aspartate transaminase and alkaline phosphatase as well as total plasma bilirubin concentrations) were assessed, and along with histology, were used to define structural and functional changes in the liver. Circulatory markers of impaired metabolism (lactate dehydrogenase, urea and oral glucose tolerance test), oxidative stress (malondialdehyde and uric acid) and inflammation (C-reactive protein; CRP) were measured.

\section{Materials and methods}

\section{Purple carrot juice}

Purple carrot juice was prepared by SDS Beverages Pty Ltd (Irymple, VIC, Australia). Purple carrots were crushed in a hammer mill with water acidified with citric acid. Following separation of solids, pectinases were added to the juice and mixed at $50-55^{\circ} \mathrm{C}$ for clarification. The juice was then subjected to pasteurisation, chilling and filtering through a $200 \mu \mathrm{m}$ mesh before evaporation was carried out to concentrate the juice to 60 brix. This 60 brix purple carrot juice was processed through another $200 \mu \mathrm{m}$ mesh and a metal analyser and stored at $4{ }^{\circ} \mathrm{C}$. This product was added as a $5 \%$ supplement to either the maize starch or high-carbohydrate, high-fat diet described below (Table 1).

Total monomeric anthocyanins were determined using the $\mathrm{pH}$ differential method as previously described ${ }^{(37)}$. Absorbance was measured at 520 and $700 \mathrm{~nm}$. Total monomeric anthocyanins were expressed as cyanidin-3-glucoside (molar extinction coefficient of 26900 litres/cm per mol and molecular weight of $449.2 \mathrm{~g} / \mathrm{mol}$ ).

Carotenoid concentrations in purple carrot juice were analysed on an Agilent 1100 series HPLC system equipped with a photodiode array UV-visible detector (Agilent Technologies, Waldbronn, Germany). Separations were achieved on a $150 \times 3.0 \mathrm{~mm}$ internal diameter, $3 \mu \mathrm{m}$ particle size, analytical scale YMC C30 reversed-phase column (YMC, Wilmington, MA, USA). Elution was performed at a solvent flow rate of $1.0 \mathrm{ml} / \mathrm{min}$ and detection at $450 \mathrm{~nm}$. The mobile phases consisted of acetone and Milli-Q water. For routine analysis, a 10-95\% linear gradient elution of acetonitrile and Milli-Q water was pumped through the column at $1.0 \mathrm{ml} / \mathrm{min}$ over $30 \mathrm{~min}$. All solvents were HPLC grade and contained $0.005 \%$ trifluoroacetic acid (Sigma-Aldrich Australia, Sydney, NSW, Australia) to enhance peak shape. Purple carrot juice was dissolved in $100 \%$ analytical grade methanol and filtered through a Whatman polytetrafluoroethylene (PTFE) membrane filter $(0.45 \mu \mathrm{m} ;$ Whatman PLC, Maidstone, Kent, UK) before loading the sample $(10 \mu \mathrm{l}$ injection volume). The UV spectra of the different carotenoid (all-trans- $\beta$-carotene, zeaxanthin and lutein) compounds were recorded with a diode array detector. Carotenoids were quantified using calibration curves of the corresponding standard compounds at the specific absorption maximum. 
Table 1. Diet composition and energy contents of diets

\begin{tabular}{|c|c|c|c|c|c|c|}
\hline Ingredient & M & MC & MP & $\mathrm{H}$ & $\mathrm{HC}$ & HP \\
\hline Maize starch (g/kg) & 570.00 & 570.00 & $570 \cdot 00$ & - & - & - \\
\hline Powdered rat feed $(\mathrm{g} / \mathrm{kg})^{\star}$ & 155.00 & 155.00 & 155.00 & $155 \cdot 00$ & $155 \cdot 00$ & $155 \cdot 00$ \\
\hline HMW salt mixture $(\mathrm{g} / \mathrm{kg}) \dagger$ & $25 \cdot 00$ & 25.00 & $25 \cdot 00$ & $25 \cdot 00$ & 25.00 & 25.00 \\
\hline Fructose (g/kg) & - & - & - & $175 \cdot 00$ & $175 \cdot 00$ & $175 \cdot 00$ \\
\hline Beef tallow $(\mathrm{g} / \mathrm{kg})$ & - & - & - & $200 \cdot 00$ & $200 \cdot 00$ & $200 \cdot 00$ \\
\hline Condensed milk ( $/ \mathrm{kg})$ & - & - & - & 395.00 & 395.00 & 395.00 \\
\hline Water (ml/kg) & $250 \cdot 00$ & $250 \cdot 00$ & $200 \cdot 00$ & $50 \cdot 00$ & $50 \cdot 00$ & - \\
\hline Purple carrot juice (ml/kg) & - & - & $50 \cdot 00$ & - & - & $50 \cdot 00$ \\
\hline$\beta$-Carotene $(\mathrm{mg} / \mathrm{kg})$ & - & 400 & - & - & 400 & - \\
\hline Energy $(\mathrm{kJ} / \mathrm{g})$ & $11 \cdot 23$ & $11 \cdot 23$ & 11.67 & $17 \cdot 93$ & $17 \cdot 93$ & $18 \cdot 37$ \\
\hline \multicolumn{7}{|l|}{ Macronutrient compositionł } \\
\hline Total carbohydrates $(\mathrm{g} / \mathrm{kg})$ & $600 \cdot 25$ & $600 \cdot 25$ & $600 \cdot 25$ & $515 \cdot 67$ & 515.67 & $515 \cdot 67$ \\
\hline Total fat $(\mathrm{g} / \mathrm{kg})$ & 8.07 & 8.07 & 8.07 & 239.04 & 239.04 & 239.04 \\
\hline Total proteins $(\mathrm{g} / \mathrm{kg}) \S$ & 31.78 & $31 \cdot 78$ & 31.78 & $58 \cdot 12$ & $58 \cdot 12$ & $58 \cdot 12$ \\
\hline Total fibres $(\mathrm{g} / \mathrm{kg})$ & 7.44 & 7.44 & 7.44 & 7.44 & 7.44 & 7.44 \\
\hline Total vitamins (g/kg) & 0.32 & 0.32 & 0.32 & 0.32 & 0.32 & 0.32 \\
\hline Retinol (mg/kg) & 4.0 & 4.0 & 4.0 & 4.0 & 4.0 & 4.0 \\
\hline Total minerals $(\mathrm{g} / \mathrm{kg}) \S$ & 0.13 & 0.13 & 0.13 & 0.44 & 0.44 & 0.44 \\
\hline Ash $(\mathrm{g} / \mathrm{kg})$ & 0.63 & 0.63 & 0.63 & 0.00 & 0.00 & 0.00 \\
\hline Total moisture $(\mathrm{g} / \mathrm{kg})$ & $326 \cdot 4$ & $326 \cdot 4$ & $276 \cdot 4$ & $154 \cdot 0$ & $154 \cdot 0$ & $104 \cdot 0$ \\
\hline
\end{tabular}

M, maize starch diet; $M C$, maize starch $+\beta$-carotene diet; MP, maize starch + purple carrot juice diet; $\mathrm{H}$, high-carbohydrate, high-fat diet; $\mathrm{HC}$, highcarbohydrate, high-fat $+\beta$-carotene diet; HP, high-carbohydrate, high-fat + purple carrot juice diet.

${ }^{*}$ Meat-free rat and mouse feed (Specialty Feeds) contained (g/kg feed): carbohydrate, 707.07; protein, 194.00; fat, 48.00; fibre, 48.00; total vitamins, 2.08; total minerals, 0.85 .

†Hubble, Mendel and Wakeman salt mixture ${ }^{(54)}$ (MP Biochemicals, Seven Hills, NSW, Australia).

$\ddagger$ Derived from powdered rat feed.

$\S \mathrm{H}, \mathrm{HC}$ and $\mathrm{HP}$ diets additionally derive these micronutrients from condensed milk.

Rats

The experimental groups consisted of eighty-four male Wistar rats (aged 8-9 weeks; weight $337 \pm 5 \mathrm{~g}$ ) supplied by The University of Queensland Biological Resources unit and individually housed at the School of Biomedical Sciences Animal House Facility. All experimental procedures were approved by the Animal Experimentation Ethics Committee of The University of Queensland under the guidelines of the National Health and Medical Research Council of Australia. All experimental groups were housed in a temperaturecontrolled, $12 \mathrm{~h}$ light-dark cycle environment with ad libitum access to water and the group-specific rat diet. Daily body weight, feed and water measurements were taken to monitor the day-to-day health of the rats. The rats were randomly divided into six separate groups based on their diet: maize starch ( $n$ 12); maize starch $+\beta$-carotene $(n 12)$; maize starch + purple carrot juice ( $n$ 12); high-carbohydrate, high-fat $(\mathrm{H}$; $n$ 24); high-carbohydrate, high-fat $+\beta$-carotene (HC; $n$ 12); high-carbohydrate, high-fat + purple carrot juice (HP; $n$ 12). The full description of the diets is given in Table 1. In addition, the drinking water of all high-carbohydrate, high-fat diet-fed rats contained $25 \%$ fructose. Both purple carrot juice and $\beta$-carotene (Sigma-Aldrich Australia) were administered for 8 weeks starting 8 weeks after the initiation of the maize starch or high-carbohydrate, high-fat diets. Twelve rats were killed from the high-carbohydrate, high-fat diet group at 8 weeks to assess the pathophysiological state before purple carrot or $\beta$-carotene intervention ( $\mathrm{H} 8$ weeks). Two rats per group were taken for histological analysis. Two slides were prepared per tissue specimen and two random, nonoverlapping fields pictured for analysis. Organs were also collected from rats used for perfusion studies.
Systolic blood pressure was measured under light sedation with intraperitoneal injection of Zoletil (tiletamine $15 \mathrm{mg} / \mathrm{kg}$, zolazepam $15 \mathrm{mg} / \mathrm{kg}$; Virbac, Peakhurst, NSW, Australia). Measurements were taken using an MLT1010 Piezo-Electric Pulse Transducer (ADInstruments, Sydney, NSW, Australia) and inflatable tail-cuff connected to a MLT844 Physiological Pressure Transducer (ADInstruments) and PowerLab data acquisition unit (ADInstruments).

For the oral glucose tolerance test, basal blood glucose concentrations were measured in tail-vein blood using a Medisense Precision Q.I.D glucose meter (Abbott Laboratories, Bedford, MA, USA) after an overnight (10-12 h) feed deprivation. Fructose-supplemented drinking water in $\mathrm{H}, \mathrm{HC}$ and $\mathrm{HP}$ groups was replaced with normal water for the overnight feed-deprivation period for the measurement of basal blood glucose concentrations. The rats were given glucose at $2 \mathrm{~g} / \mathrm{kg}$ body weight as a $40 \%$ solution via oral administration. Tail-vein blood samples were taken at 0,30 , 60, 90 and $120 \mathrm{~min}$ following glucose administration.

\section{Echocardiography}

Echocardiographic examination (Philips iE33 system, $12 \mathrm{MHz}$ transducer; Philips Medical System, Andover, MA, USA) was performed at 8 and 16 weeks as previously described ${ }^{(35,38)}$. Briefly, rats were anaesthetised using intraperitoneal Zoletil (toletamine $15 \mathrm{mg} / \mathrm{kg}$ and zolazepam $15 \mathrm{mg} / \mathrm{kg}$ intraperitoneally; Virbac, Peakhurst, NSW, Australia) combined with xylazine $(10 \mathrm{mg} / \mathrm{kg})$ (Ilium Xylazil; Troy Laboratories, Sydney, NSW, Australia) and positioned in dorsal recumbency. Electrodes attached to the skin overlying the elbows and right stifle facilitated the simultaneous recording of a lead II electrocardiogram. 
A short axis view of the left ventricle at the level of the papillary muscles was obtained and used for direct acquisition of M-mode images of the left ventricle for measurement of diastolic posterior wall thickness, left ventricular internal systolic dimension and left ventricular end-diastolic diameter. For these parameters, diastole was defined by the beginning of the QRS complex on the simultaneously recorded electrocardiogram and systole identified as the nadir of systolic anterior wall motion independent of the electrocardiogram complex.

Pulsed-wave Doppler velocity profiles of mitral inflow was obtained from the left apical four-chamber view for measurement of early $\left(E_{M}\right)$ and late $\left(A_{M}\right)$ mitral inflow velocity, mitral inflow E-wave deceleration time, and time from mitral valve closure to opening (MCMO). A pulsed-wave Doppler velocity profile of the ascending aorta was obtained from a suprasternal view for measurement of aortic (Ao) velocity, ejection time (ET) and the diameter of the ascending aorta at the point of transition to the transverse aorta.

Derived indices of left ventricular systolic function (fractional shortening (FS\%), ejection fraction (EF\%)) were calculated using well-established formulae ${ }^{(38)}$. Left ventricular mass was estimated using the standard cube equation as previously described ${ }^{(35,38)}$.

\section{Isolated heart preparation}

The left ventricular function of the rats in all treatment groups was assessed using the Langendorff heart preparation. Terminal anaesthesia was induced via intraperitoneal injection of pentobarbitone sodium (Lethabarb ${ }^{\circledR}, 100 \mathrm{mg} / \mathrm{kg}$ ). After heparin (Sigma-Aldrich Australia) administration (100 IU) through the right femoral vein, blood (about $5 \mathrm{ml}$ ) was taken from the abdominal aorta. Isovolumetric ventricular function was measured by inserting a latex balloon catheter into the left ventricle connected to a Capto SP844 MLT844 physiological pressure transducer and Chart software on a Maclab system (ADInstruments Australia and Pacific Islands, Bella Vista, NSW, Australia). All left ventricular end-diastolic pressure values were measured while pacing the heart at 250 beats per min using an electrical stimulator. End-diastolic pressures were obtained starting from $0 \mathrm{mmHg}$ up to $30 \mathrm{mmHg}$. The diastolic stiffness constant ( $\kappa$, dimensionless) was calculated as in previous studies ${ }^{(35,39)}$.

\section{Organ bath studies}

Thoracic aortic rings ( $4 \mathrm{~mm}$ in length) were suspended in an organ bath chamber with a resting tension of $10 \mathrm{mN}$. Cumulative concentration-response (contraction) curves were measured for noradrenaline (Sigma-Aldrich Australia); concentration-response (relaxation) curves were measured for acetylcholine (Sigma-Aldrich Australia) and sodium nitroprusside (Sigma-Aldrich Australia) in the presence of a submaximal $(70 \%)$ contraction to noradrenaline ${ }^{(35)}$.

\section{Organ weights}

The right and left ventricles were separated after perfusion experiments and weighed. Liver and abdominal fat were removed following heart removal and blotted dry for weighing. Perirenal, epididymal and omental fat were together weighed as abdominal fat. Organ weights were normalised relative to the tibial length at the time of their removal (in $\mathrm{mg} / \mathrm{mm}$ ).

\section{Histology}

Immediately after removal, heart and liver tissues were fixed in $10 \%$ buffered formalin for $3 \mathrm{~d}$ with change of formalin every day to remove traces of blood from the tissue. The samples were then dehydrated and embedded in paraffin wax. Thin sections $(10 \mu \mathrm{m})$ of left ventricle and the liver were cut and stained with haematoxylin and eosin stain for determination of inflammatory cell infiltration. Liver sections were also stained with Milligan's Trichrome stain to determine fibrosis. Collagen distribution was measured in the left ventricle with picrosirius red stain. Laser confocal microscopy (Zeiss LSM 510 upright Confocal Microscope) ${ }^{(35)}$ with colour intensity quantitatively analysed using NIH-imageJ software (National Institutes of Health, Bethesda, MD, USA) was used to determine the extent of collagen deposition in selected tissue sections.

\section{Plasma analysis}

Briefly, blood was centrifuged at $5000 \mathrm{~g}$ for $15 \mathrm{~min}$ within 30 min after collection into heparinised tubes. Plasma samples were separated and transferred to Eppendorf tubes for analysis. Plasma enzymic activities and analyte concentrations were determined using kits and controls supplied by Olympus using an Olympus analyser (AU 400; Olympus, Tokyo, Japan): cholesterol, Olympus OSR6516 enzymic colour test; TAG, Olympus OSR 6133 enzymic colour test; lactate dehydrogenase, Olympus OSR6127 kinetic UV test; urea, Olympus OSR 6134 kinetic UV test; uric acid, Olympus OSR 6098 enzymic colour test; alanine transaminase, Olympus OSR 6107 kinetic UV test; aspartate transaminase, Olympus OSR 6109 kinetic UV test; alkaline phosphatase, Olympus OSR 6004 knetic UV test; albumin, Olympus OSR 6101 photometric colour test; total bilirubin, Olympus OSR 6111 photometric colour test. Globulin was calculated as total protein-albumin. Plasma malondialdehyde concentrations were measured by HPLC (Shimadzu ${ }^{\circledR}$ ) as previously described $^{(40)}$. Plasma CRP was estimated using a commercial kit (Kamiya Biomedical, CA, USA) according to manufacturerprovided standards and protocols using a Cobas-Mira automated analyzer (Roche Diagnostics, Basel, Switzerland).

\section{Statistical analysis}

All data are presented as mean values with their standard errors. Results were tested for variance using Bartlett's test and data that were not normally distributed were transformed (using log 10 function) before statistical analyses. Differences between the groups were determined by one-way ANOVA with the Newman-Keuls multiple comparison post test. For non-parametric data (total plasma cholesterol, plasma NEFA, lactate dehydrogenase, malondialdehyde and plasma urea concentrations and feed intake), Kruskal-Wallis tests were performed. All statistical analysis was performed using GraphPad Prism version 5.00 for Windows (San Diego, CA, USA). $P<0.05$ was considered as statistically significant. 


\section{Results}

Diet and supplement intake, body weight and metabolic parameters

Purple carrot juice contained anthocyanins (total $5.53 \mathrm{mg} / \mathrm{ml}$ ) and traces of $\beta$-carotene $(0.75 \mu \mathrm{g} / \mathrm{ml})$, lutein $(0.54 \mu \mathrm{g} / \mathrm{ml})$ and zeaxanthin $(4.4 \mu \mathrm{g} / \mathrm{ml})$. The mean daily intakes of total anthocyanins and carotenoids were higher in the maize starch + purple carrot juice and maize starch $+\beta$-carotene groups than in the HP and $\mathrm{HC}$ groups, respectively, as the feed intake was higher in all maize starch diet-fed rats (Table 2). However, the carotenoid intakes in the maize starch + purple carrot juice and HP rats were extremely low due to the low carotenoid content of the juice (Table 2).

The high-carbohydrate, high-fat diet induced an increased body weight, especially with increased abdominal fat pads and abdominal circumference, compared with maize starch diet-fed rats (Table 2). Although high-carbohydrate, high-fat diet feeding reduced feed and water intake, rats on this diet had higher daily energy intake compared with maize starch diet-fed rats (Table 2). Neither purple carrot juice nor $\beta$-carotene supplementation altered daily feed, water or energy intake. However, purple carrot juice supplementation reduced percentage gain in body weight, abdominal fat pads and abdominal circumference (Table 2). The high-carbohydrate, high-fat diet produced impaired glucose tolerance, increased plasma concentrations of total cholesterol, TAG, NEFA, malondialdehyde, CRP and uric acid, increased lactate dehydrogenase activity and decreased plasma urea concentration (Table 2). Purple carrot juice supplementation improved oral glucose tolerance (Table 2) and reduced plasma total cholesterol, TAG, NEFA and CRP concentrations (Table 2). Although $\beta$-carotene improved oral glucose tolerance and reduced plasma CRP concentrations (Table 2), it further increased plasma TAG and NEFA concentrations (Table 2). Further, purple carrot juice supplementation attenuated the changes in lactate dehydrogenase activity, plasma uric acid, malondialdehyde and urea concentrations in high-carbohydrate, high-fat diet-fed rats; these parameters were unaltered by $\beta$-carotene supplementation (Table 2).

\section{Cardiovascular structure and function}

High-carbohydrate, high-fat diet-fed rats showed increased left ventricular diastolic internal diameter and relative wall thickness with increased estimated left ventricular mass and wet weight in comparison with the maize starch diet-fed rats (Table 3). Moreover, the high-carbohydrate, high-fat diet reduced fractional shortening and ejection fraction and increased ejection time (Table 3). Both $\beta$-carotene and purple carrot juice supplementation reduced estimated left ventricular mass and wet weight. In addition, $\beta$-carotene reduced left ventricular diastolic internal diameter, increased fractional shortening and ejection fraction and decreased ejection time (Table 3). High-carbohydrate, high-fat diet-fed rats showed sustained elevation in systolic blood pressure after 4 weeks of diet administration as compared with maize starch diet-fed rats (Table 3). Purple carrot juice as well as $\beta$-carotene supplementation normalised blood pressure as early as 4 weeks post-intervention (Table 3). Following high-carbohydrate, high-fat diet feeding for 16 weeks, diminished vascular responses were observed in isolated thoracic aortic rings to noradrenaline, sodium nitroprusside and acetylcholine when compared with maize starch diet-fed rats (Fig. 1). However, this reduced thoracic aortic reactivity was not observed after 8 weeks of high-carbohydrate, high-fat diet feeding. Purple carrot juice and $\beta$-carotene supplementation prevented any further decrease in sodium nitroprusside- and acetylcholine-dependent vasorelaxation (Fig. 1(B) and (C)) as compared with high-carbohydrate, high-fat diet-fed rats at 8 weeks but failed to attenuate the reduced contractility with noradrenaline (Fig. 1(A)).

Ex vivo cardiac function as measured in the Langendorff isolated heart showed an increased diastolic stiffness (Table 3) in the high-carbohydrate, high-fat diet-fed rats as compared with the maize starch diet-fed group (Table 3). Reduction in diastolic stiffness was only observed in purple carrot juice-supplemented rats. Histological analysis revealed that high-carbohydrate, high-fat diet-fed rats showed increased infiltration by inflammatory cells into the left ventricle (Fig. 2(E)) and increased interstitial collagen deposition and hypertrophy (Fig. 2(I); Table 3) when compared with the maize starch diet-fed rats (Fig. 2(A) and (H); Table 3). Both purple carrot juice- and $\beta$-carotene-supplemented highcarbohydrate, high-fat diet-fed rats showed normalised infiltration of inflammatory cells (Fig. 2(G); Fig. 2(F)) and reduced collagen deposition with normalised hypertrophy (Fig. 2(N); Fig. 2(M); Table 3). No major changes were observed in purple carrot juice- and $\beta$-carotene-supplemented maize starch diet-fed rats (Fig. 2(B), (C), (I) and (J); Table 3).

\section{Hepatic structure and function}

In comparison with maize starch diet-fed rats, highcarbohydrate, high-fat diet-fed rats had elevated plasma alanine transaminase, aspartate transaminase and alkaline phosphatase activities although the albumin:globulin ratio and plasma bilirubin concentrations remained unaffected (Table 4). Purple carrot juice supplementation reversed liver function abnormalities indicated by normalised activity of these enzymes (Table 4). Although $\beta$-carotene supplementation normalised transaminases activities in high-carbohydrate, high-fat diet-fed rats, alkaline phosphatase activity remained elevated (Table 4).

By histological examination, high-carbohydrate, high-fat diet feeding to rats caused macrovesicular steatosis (Fig. 3(E)) resulting from accumulation of lipids in large and small droplets within hepatocytes with markedly high portal inflammation (Fig. 3(M)) and portal fibrosis (Fig. 3(T); Table 4) as compared with the maize starch diet-fed rats (Fig. 3(A), (H) and (P); Table 4). The purple carrot juice-supplemented high-carbohydrate, high-fat diet-fed rats displayed minimal signs of macrovesicular steatosis (Fig. 3(G)), portal inflammation (Fig. 3(O)) or fibrosis (Fig. 3(V); Table 4). The $\beta$-carotene-supplemented high-carbohydrate, high-fat diet-fed rats displayed normalised portal inflammation (Fig. 3(N)) and fibrosis (Fig. 3(P); Table 4) but showed obvious hepatocyte ballooning and increased fat vacuole size and number (Fig. 3(F)). No major hepatic changes were observed in purple carrot juice- and $\beta$-carotene-supplemented maize starch dietfed rats (Fig. 3(C), (K) and (R) and 3(B), (J) and (Q); Table 4). 
Table 2. Changes in dietary intakes, body anthropometrics, blood and plasma biochemistry

(Mean values with their standard errors for ten animals per group)

\begin{tabular}{|c|c|c|c|c|c|c|c|c|c|c|c|c|c|c|}
\hline \multirow[b]{2}{*}{ Parameter } & \multicolumn{2}{|c|}{ M } & \multicolumn{2}{|l|}{ MC } & \multicolumn{2}{|c|}{ MP } & \multicolumn{2}{|c|}{ H (8 weeks) } & \multicolumn{2}{|c|}{$\mathrm{H}$ (16 weeks) } & \multicolumn{2}{|c|}{$\mathrm{HC}$} & \multicolumn{2}{|c|}{ HP } \\
\hline & Mean & SEM & Mean & SEM & Mean & SEM & Mean & SEM & Mean & SEM & Mean & SEM & Mean & SEM \\
\hline \multicolumn{15}{|l|}{ Dietary intakes } \\
\hline Feed $(\mathrm{g} / \mathrm{d})$ & $33 \cdot 0^{\mathrm{j}, \mathrm{k}}$ & 2.9 & $34 \cdot 4^{i}$ & 1.5 & $29 \cdot 0^{\mathrm{g}, \mathrm{h}, \mathrm{i}, \mathrm{j}}$ & 2.6 & $21 \cdot 0^{\mathrm{c}, \mathrm{d}, \mathrm{e}}$ & $2 \cdot 0$ & $22 \cdot 4^{\mathrm{b}, \mathrm{d}, \mathrm{f}, \mathrm{g}}$ & $2 \cdot 0$ & $23 \cdot 5^{a, e, f}$ & 0.6 & $19 \cdot 6^{\mathrm{a}, \mathrm{b}, \mathrm{c}, \mathrm{h}}$ & $2 \cdot 1$ \\
\hline Water $(\mathrm{ml} / \mathrm{d})$ & $25 \cdot 5^{\mathrm{k}, \mathrm{l}}$ & $2 \cdot 3$ & $30 \cdot 7^{1}$ & 0.8 & $22 \cdot 9^{\mathrm{d}, \mathrm{e}, \mathrm{i}, \mathrm{j}, \mathrm{k}}$ & $2 \cdot 6$ & $18 \cdot 0^{c, e, f, g}$ & 2.0 & $18 \cdot 4^{\mathrm{b}, \mathrm{f}, \mathrm{h}, \mathrm{i}}$ & $2 \cdot 0$ & $17 \cdot 3^{\mathrm{a}, \mathrm{b}, \mathrm{c}, \mathrm{d}}$ & 0.4 & $19 \cdot 1^{a, g, h, j}$ & 1.9 \\
\hline Total energy $(\mathrm{kJ} / \mathrm{d})$ & $375 \cdot 0^{\mathrm{a}, \mathrm{b}}$ & 15 & $396 \cdot 1^{\mathrm{b}, \mathrm{c}}$ & $17 \cdot 4$ & $343 \cdot 0^{\mathrm{a}}$ & $16 \cdot 0$ & $459.0^{d}$ & $10 \cdot 0$ & $454.0^{d}$ & $6 \cdot 0$ & $494 \cdot 8^{d}$ & 12.4 & $431 \cdot 0^{\mathrm{c}, \mathrm{d}}$ & $15 \cdot 0$ \\
\hline $\begin{array}{l}\text { Total anthocyanins } \\
(\mathrm{mg} / \mathrm{kg})\end{array}$ & $0.0^{\mathrm{a}}$ & 0.0 & $0.0^{\mathrm{a}}$ & 0.0 & 24.4 & 1.0 & $0.0^{\mathrm{a}}$ & 0.0 & $0.0^{\mathrm{a}}$ & 0.0 & $0.0^{\mathrm{a}}$ & 0.0 & $15 \cdot 2$ & 0.4 \\
\hline $\begin{array}{l}\text { Total } \beta \text {-carotene } \\
(\mathrm{mg} / \mathrm{kg})\end{array}$ & $0.0^{\mathrm{a}}$ & 0.0 & $30 \cdot 8$ & $1 \cdot 1$ & $0.0027^{\mathrm{a}}$ & 0.0001 & $0.0^{\mathrm{a}}$ & 0.0 & $0.0^{\mathrm{a}}$ & 0.0 & $22 \cdot 1$ & 0.6 & $0.0017^{\mathrm{a}}$ & 0.00002 \\
\hline Total lutein $(\mathrm{mg} / \mathrm{kg})$ & $0.0^{\mathrm{a}}$ & 0.0 & $0.0^{\mathrm{a}}$ & 0.0 & 0.002 & 0.0001 & $0.0^{\mathrm{a}}$ & 0.0 & $0.0^{\mathrm{a}}$ & 0.0 & $0.0^{\mathrm{a}}$ & 0.0 & 0.0012 & 0.00002 \\
\hline $\begin{array}{l}\text { Total zeaxanthin } \\
(\mathrm{mg} / \mathrm{kg})\end{array}$ & $0.0^{\mathrm{a}}$ & 0.0 & $0.0^{\mathrm{a}}$ & 0.0 & 0.0164 & 0.0001 & $0.0^{\mathrm{a}}$ & 0.0 & $0.0^{\mathrm{a}}$ & 0.0 & $0.0^{\mathrm{a}}$ & 0.0 & 0.0104 & 0.0002 \\
\hline \multicolumn{15}{|l|}{ Body anthropometrics } \\
\hline $\begin{array}{l}\text { Body-weight } \\
\text { gain }(\%)^{*}\end{array}$ & $10 \cdot 8^{\mathrm{b}, \mathrm{e}, \mathrm{f}}$ & 0.6 & $10 \cdot 7^{\mathrm{c}, \mathrm{d}, \mathrm{e}}$ & 1 & $5 \cdot 4$ & 0.9 & $30 \cdot 0$ & 0.8 & $14 \cdot 3^{\mathrm{g}}$ & 0.9 & $12 \cdot 8^{\mathrm{a}, \mathrm{d}, \mathrm{f}, \mathrm{g}}$ & 0.7 & $10 \cdot 6^{a, b, c}$ & 0.6 \\
\hline $\begin{array}{l}\text { Abdominal } \\
\text { circumference }(\mathrm{cm})\end{array}$ & $18 \cdot 4^{\mathrm{b}, \mathrm{c}, \mathrm{d}}$ & 0.3 & $17 \cdot 9^{\mathrm{a}, \mathrm{b}}$ & 0.2 & $19 \cdot 3^{\mathrm{c}, \mathrm{e}}$ & 0.3 & $18 \cdot 7^{\mathrm{a}, \mathrm{d}, \mathrm{e}}$ & 0.4 & $22 \cdot 9$ & 0.3 & $21 \cdot 1$ & 0.2 & $20 \cdot 2$ & 0.4 \\
\hline $\begin{array}{l}\text { Abdominal fat } \\
\text { pads }(\mathrm{mg} / \mathrm{mm})\end{array}$ & $401^{\mathrm{b}, \mathrm{c}, \mathrm{d}}$ & 56 & $211 \cdot 7^{\mathrm{a}}$ & $19 \cdot 4$ & $264^{\mathrm{a}}$ & 18 & $421^{\mathrm{d}, \mathrm{e}, \mathrm{f}}$ & $2 \cdot 6$ & 781.0 & $48 \cdot 0$ & $521 \cdot 6^{\mathrm{b}, \mathrm{e}, \mathrm{g}}$ & 29.4 & $452^{\mathrm{c}, \mathrm{f}, \mathrm{g}}$ & 31 \\
\hline \multicolumn{15}{|l|}{$\begin{array}{l}\text { Oral glucose } \\
\text { tolerance }(\mathrm{AUC}) \\
(\mathrm{mmol} / \mathrm{l} \times \mathrm{min})\end{array}$} \\
\hline Week 0 & $769 \cdot 0^{a}$ & $17 \cdot 4$ & $763.8^{\mathrm{a}}$ & $15 \cdot 4$ & $771.5^{\mathrm{a}}$ & 13.5 & - & - & $738.7^{\mathrm{a}}$ & 25.5 & $755.4^{\mathrm{a}}$ & $9 \cdot 4$ & $761 \cdot 9^{a}$ & $7 \cdot 0$ \\
\hline Week 8 & $682 \cdot 4^{a}$ & 18.7 & $685 \cdot 9^{\mathrm{a}}$ & 18.9 & $683.6^{\mathrm{a}}$ & 20.0 & - & - & $831.4^{\mathrm{b}}$ & 17.1 & $826 \cdot 6^{\mathrm{b}}$ & 24.0 & $835 \cdot 6^{\mathrm{b}}$ & 22.7 \\
\hline Week 16 & $688 \cdot 7^{\mathrm{c}, \mathrm{f}, \mathrm{g}}$ & 24.9 & $651 \cdot 7^{\mathrm{a}, \mathrm{e}, \mathrm{f}}$ & 20.1 & $588 \cdot 1^{\mathrm{a}, \mathrm{b}}$ & 12.2 & _- & _ & 875.1 & 19.9 & $625 \cdot 1^{\mathrm{b}, \mathrm{c}, \mathrm{d}, \mathrm{f}}$ & 24.5 & $679 \cdot 6^{\mathrm{d}, \mathrm{g}}$ & 20.7 \\
\hline \multicolumn{15}{|l|}{ Plasma lipids (mmol/l) } \\
\hline Total cholesterol & $1.6^{\mathrm{b}}$ & 0.07 & $1 \cdot 6^{\mathrm{a}, \mathrm{b}, \mathrm{c}}$ & 0.1 & $1.5^{\mathrm{a}, \mathrm{b}, \mathrm{c}}$ & 0.05 & $2 \cdot 0^{a, b, c}$ & 0.2 & $2 \cdot 1^{\mathrm{c}}$ & 0.2 & $1.9^{a, b, c}$ & 0.1 & $1 \cdot 6^{\mathrm{a}, \mathrm{b}}$ & 0.06 \\
\hline TAG & $0.5^{\mathrm{d}, \mathrm{e}, \mathrm{f}, \mathrm{g}}$ & 0.06 & $0.5^{\mathrm{c}, \mathrm{g}, \mathrm{h}, \mathrm{i}, \mathrm{j}}$ & 0.05 & $0.3^{a, b, c, d}$ & 0.02 & $0.5^{\mathrm{b}, \mathrm{f}, \mathrm{j}, \mathrm{k}}$ & 0.2 & $1 \cdot 2^{\mathrm{h}}$ & 0.1 & 1.9 & 0.4 & $0.5^{\mathrm{a}, \mathrm{e}, \mathrm{i}, \mathrm{k}}$ & 0.1 \\
\hline NEFA & $0.9^{b, c, d}$ & 0.1 & $2 \cdot 4^{\dagger}$ & 0.3 & $0.9^{\mathrm{a}, \mathrm{d}, \mathrm{e}}$ & 0.1 & $0 \cdot 7^{\mathrm{a}, \mathrm{b}}$ & 0.01 & $2 \cdot 1^{\dagger}$ & 0.06 & 4.8 & 0.7 & $1.0^{\mathrm{c}, \mathrm{e}}$ & 0.1 \\
\hline \multicolumn{15}{|l|}{$\begin{array}{l}\text { Plasma oxidative } \\
\text { stress markers } \\
\text { (umol/l) }\end{array}$} \\
\hline Malondialdehyde & $27 \cdot 0^{\mathrm{a}, \mathrm{b}, \mathrm{c}}$ & 0.6 & $28 \cdot 2^{\mathrm{c}, \mathrm{d}, \mathrm{e}, \mathrm{f}}$ & 0.4 & $28 \cdot 5^{\mathrm{b}, \mathrm{f}, \mathrm{g}, \mathrm{h}}$ & 0.7 & $30 \cdot 7^{\mathrm{d}, \mathrm{g}, \mathrm{i}, \mathrm{j}, \mathrm{k}}$ & 0.7 & $32 \cdot 2^{\mathrm{j}, \mathrm{I}}$ & 1.2 & $32 \cdot 1^{\mathrm{k}, \mathrm{l}}$ & $1 \cdot 1$ & $28 \cdot 5^{\mathrm{a}, \mathrm{e}, \mathrm{h}, \mathrm{i}}$ & $1 \cdot 1$ \\
\hline Uric acid & $27 \cdot 2^{\mathrm{a}}$ & 1.6 & $53 \cdot 2^{\mathrm{d}, \mathrm{h}, \mathrm{i}, \mathrm{j}}$ & 6.4 & $58.9^{\mathrm{b}, \mathrm{f}, \mathrm{i}, \mathrm{k}}$ & $5 \cdot 3$ & $42 \cdot 5^{\mathrm{b}, \mathrm{c}, \mathrm{d}, \mathrm{e}}$ & 3.1 & $58 \cdot 1^{\mathrm{c}, \mathrm{g}, \mathrm{j}, \mathrm{k}}$ & 5.7 & $46 \cdot 4^{e, f, g, h}$ & 2.0 & $22 \cdot 7^{\mathrm{a}}$ & 1.5 \\
\hline $\operatorname{CRP}(\mu \mathrm{mol} / \mathrm{l})$ & $59 \cdot 3^{\mathrm{c}, \mathrm{g}, \mathrm{j}, \mathrm{l}}$ & 7.4 & $49 \cdot 3^{\mathrm{a}, \mathrm{d}, \mathrm{g}, \mathrm{h}, \mathrm{i}}$ & 10.6 & $46^{\mathrm{b}, \mathrm{c}, \mathrm{d}, \mathrm{e}, \mathrm{f}}$ & 7.3 & $58 \cdot 1^{\mathrm{e}, \mathrm{h}, \mathrm{k}, \mathrm{l}}$ & 7.4 & 102.3 & 4.6 & $57 \cdot 5^{\mathrm{f}, \mathrm{i}, \mathrm{j}, \mathrm{k}}$ & 6.2 & $23 \cdot 5^{a, b}$ & 9.2 \\
\hline $\begin{array}{l}\text { Lactate } \\
\quad \text { dehydrogenase (U/I) }\end{array}$ & $201 \cdot 0^{a, b, c, d}$ & $28 \cdot 1$ & $277 \cdot 8^{\mathrm{b}, \mathrm{f}, \mathrm{j}, \mathrm{k}, \mathrm{l}, \mathrm{m}}$ & $35 \cdot 1$ & $208 \cdot 9^{\mathrm{d}, \mathrm{e}, \mathrm{f}, \mathrm{g}}$ & 18.5 & $279 \cdot 8^{\mathrm{a}, \mathrm{e}, \mathrm{i}, \mathrm{m}, \mathrm{n}, \mathrm{o}}$ & $23 \cdot 2$ & $361 \cdot 8^{k, n, p}$ & 37.9 & $329 \cdot 6^{\mathrm{h}, \mathrm{l}, \mathrm{o}, \mathrm{p}}$ & 39.1 & $221 \cdot 6^{\mathrm{c}, \mathrm{g}, \mathrm{h}, \mathrm{i}, \mathrm{j}}$ & $19 \cdot 1$ \\
\hline Urea $(\mathrm{mmol} / \mathrm{l})$ & $7 \cdot 3^{\mathrm{d}, \mathrm{f}}$ & 0.5 & $4 \cdot 8^{\mathrm{a}, \mathrm{b}}$ & 0.4 & $6 \cdot 6^{\mathrm{e}, \mathrm{f}}$ & 0.6 & $5 \cdot 7^{\mathrm{b}, \mathrm{c}}$ & 0.2 & $3.8^{\mathrm{a}}$ & 0.4 & 2.4 & 0.4 & $6 \cdot 4^{c, d, e}$ & 0.1 \\
\hline
\end{tabular}

M, maize starch diet; MC, maize starch + $\beta$-carotene diet; MP, maize starch + purple carrot juice diet; $\mathrm{H}$, high-carbohydrate, high-fat diet; HC, high-carbohydrate, high-fat + $\beta$-carotene diet; HP, high-carbohydrate, high-fat + purple carrot juice diet; AUC, area under the curve; CRP, C-reactive protein.

${ }^{-\mathrm{a}}$ Mean values within a row with unlike superscript letters were significantly different $(P<0.05)$

${ }^{*}$ Body-weight gain calculated as percentage of body weight increase from 8 weeks to 16 weeks for all groups and week 1 to week 8 for the high-carbohydrate, high-fat diet-fed rats ( 8 weeks). 
Table 3. Changes in cardiovascular structure and function

(Mean values with their standard errors for ten animals per group)

\begin{tabular}{|c|c|c|c|c|c|c|c|c|c|c|c|c|c|c|}
\hline \multirow[b]{2}{*}{ Parameter } & \multicolumn{2}{|l|}{ M } & \multicolumn{2}{|l|}{ MC } & \multicolumn{2}{|l|}{ MP } & \multicolumn{2}{|c|}{ H (8 weeks) } & \multicolumn{2}{|c|}{$\mathrm{H}$ (16 weeks) } & \multicolumn{2}{|l|}{$\mathrm{HC}$} & \multicolumn{2}{|l|}{ HP } \\
\hline & Mean & SEM & Mean & SEM & Mean & SEM & Mean & SEM & Mean & SEM & Mean & SEM & Mean & SEM \\
\hline LVIDd (mm) & $6 \cdot 1^{a, b, c, j}$ & 0.2 & $6 \cdot 4^{\mathrm{c}, \mathrm{d}, \mathrm{e}, \mathrm{f}, \mathrm{g}}$ & 0.4 & $7 \cdot 0^{\mathrm{f}, \mathrm{i}, \mathrm{j}, \mathrm{k}, \mathrm{l}, \mathrm{m}}$ & 0.2 & $7 \cdot 9^{k, n, p}$ & 0.3 & $7 \cdot 4^{\mathrm{d}, \mathrm{l}, \mathrm{o}, \mathrm{p}}$ & 0.2 & $6 \cdot 5^{\mathrm{b}, \mathrm{g}, \mathrm{h}, \mathrm{i}}$ & 0.3 & $7 \cdot 1^{\mathrm{a}, \mathrm{e}, \mathrm{h}, \mathrm{m}, \mathrm{n}, \mathrm{o}}$ & 0.3 \\
\hline LVIDs (mm) & $0.4^{\mathrm{b}, \mathrm{c}, \mathrm{d}}$ & 0.01 & $0.3^{a}$ & 0.01 & $0.3^{\mathrm{a}}$ & 0.01 & 0.5 & 0.01 & $0.4^{\mathrm{d}, \mathrm{e}}$ & 0.01 & $0.4^{\mathrm{c}, \mathrm{e}}$ & 0.01 & $0.4^{\mathrm{b}, \mathrm{e}}$ & 0.01 \\
\hline LVPWd $(\mathrm{mm})$ & $1.8^{\mathrm{a}}$ & 0.1 & $1 \cdot 7^{\mathrm{a}}$ & 0.08 & $1.5^{\mathrm{a}}$ & 0.0 & $1.6^{\mathrm{a}}$ & 0.0 & $1.8^{\mathrm{a}}$ & 0.1 & $1.9^{\mathrm{a}}$ & 0.1 & $1 \cdot 6^{a}$ & 0.1 \\
\hline Relative wall thickness & $0 \cdot 4^{\mathrm{a}, \mathrm{b}, \mathrm{c}, \mathrm{d}}$ & 0.02 & $0.5^{\mathrm{k}, \mathrm{l}}$ & 0.06 & $0.4^{\mathrm{d}, \mathrm{e}, \mathrm{f}, \mathrm{g}}$ & 0.01 & $0.4^{\mathrm{c}, \mathrm{g}, \mathrm{h}, \mathrm{i}}$ & 0.01 & $0.6^{\prime}$ & 0.02 & $0.5^{\mathrm{a}, \mathrm{e}, \mathrm{h}, \mathrm{j}, \mathrm{k}}$ & 0.02 & $0.4^{\mathrm{b}, \mathrm{f}, \mathrm{i}, \mathrm{j}}$ & 0.02 \\
\hline Fractional shortening (\%) & $51 \cdot 1^{\mathrm{a}, \mathrm{b}, \mathrm{c}}$ & $2 \cdot 6$ & $54.7^{\mathrm{b}}$ & 4.0 & $50 \cdot 7^{\mathrm{a}, \mathrm{b}, \mathrm{c}}$ & 3.4 & $43 \cdot 8^{a, b, c}$ & $2 \cdot 2$ & $40 \cdot 2^{c}$ & $1 \cdot 1$ & $52 \cdot 7^{\mathrm{b}}$ & 2.6 & $43 \cdot 6^{\mathrm{a}, \mathrm{b}, \mathrm{c}}$ & 3.4 \\
\hline Ejection fraction (\%) & $88 \cdot 0^{\mathrm{e}, \mathrm{h}, \mathrm{l}, \mathrm{m}}$ & 2.0 & $90 \cdot 5^{\mathrm{k}, \mathrm{m}, \mathrm{n}}$ & $2 \cdot 2$ & $85 \cdot 3^{\mathrm{a}, \mathrm{f}, \mathrm{i}, \mathrm{j}, \mathrm{k}, \mathrm{l}}$ & $1 \cdot 8$ & $81 \cdot 6^{\mathrm{c}, \mathrm{g}, \mathrm{h}, \mathrm{i}}$ & $2 \cdot 2$ & $79 \cdot 1^{\mathrm{a}, \mathrm{c}, \mathrm{d}}$ & 1.6 & $90 \cdot 7^{i, n}$ & 1.6 & $80 \cdot 4^{\mathrm{d}, \mathrm{e}, \mathrm{f}, \mathrm{g}}$ & 3.4 \\
\hline Ejection time (ms) & $84.7^{\mathrm{a}}$ & 1.7 & $95.5^{\mathrm{a}}$ & 3.0 & $99.5^{\mathrm{a}}$ & 4.0 & $97.7^{\mathrm{a}}$ & 5.4 & $93 \cdot 0^{\mathrm{a}}$ & 1.7 & $86 \cdot 2^{\mathrm{a}}$ & 2.7 & $92 \cdot 0^{\mathrm{a}}$ & 4.4 \\
\hline Deceleration time (ms) & $56 \cdot 0^{a, b, c}$ & 4.7 & $62^{b}$ & $3 \cdot 7$ & $72 \cdot 2^{a, b, c}$ & 4.9 & $47 \cdot 0^{\mathrm{c}}$ & 4.5 & $59 \cdot 7^{\mathrm{a}, \mathrm{b}, \mathrm{c}}$ & $3 \cdot 8$ & $56 \cdot 0^{\mathrm{a}, \mathrm{b}, \mathrm{c}}$ & 4.5 & $57 \cdot 0^{\mathrm{a}, \mathrm{b}, \mathrm{c}}$ & $6 \cdot 1$ \\
\hline$E_{M}(\mathrm{~m} / \mathrm{s})$ & $0.7^{\mathrm{b}, \mathrm{c}, \mathrm{d}, \mathrm{e}, \mathrm{f}}$ & 0.04 & $0 \cdot 7^{\mathrm{a}, \mathrm{f}, \mathrm{g}, \mathrm{h}, \mathrm{i}}$ & 0.05 & $0.9^{\mathrm{j}, \mathrm{m}, \mathrm{n}}$ & 0.05 & $0.6^{\mathrm{a}, \mathrm{b}}$ & 0.03 & $0.8^{e, g, j, k, l}$ & 0.01 & $0.8^{\mathrm{d}, \mathrm{h}, \mathrm{k}, \mathrm{m}, \mathrm{o}}$ & 0.02 & $0.8^{\mathrm{c}, \mathrm{i}, \mathrm{l}, \mathrm{n}, \mathrm{o}}$ & 0.05 \\
\hline$A_{M}(\mathrm{~m} / \mathrm{s})$ & $0.4^{\mathrm{a}}$ & 0.02 & $0.4^{\mathrm{a}}$ & 0.04 & $0.5^{\mathrm{a}}$ & 0.04 & $0.4^{\mathrm{a}}$ & 0.02 & $0.5^{\mathrm{a}}$ & 0.03 & $0.5^{\mathrm{a}}$ & 0.04 & $0.5^{\mathrm{a}}$ & 0.01 \\
\hline $\mathrm{MCMO}(\mathrm{ms})$ & $131 \cdot 3^{b}$ & $7 \cdot 3$ & $117 \cdot 6^{\mathrm{a}, \mathrm{b}, \mathrm{c}}$ & 7.4 & $121 \cdot 0^{a, b, c}$ & 7.0 & $119 \cdot 0^{\mathrm{a}, \mathrm{b}, \mathrm{c}}$ & 6.9 & $105 \cdot 4^{c}$ & $4 \cdot 1$ & $105 \cdot 2^{\mathrm{C}}$ & 3.0 & $118 \cdot 8^{\mathrm{a}, \mathrm{b}, \mathrm{c}}$ & 3.5 \\
\hline Estimated left ventricle mass ( $\mathrm{g}$ ) & $0 \cdot 7^{\mathrm{a}, \mathrm{d}, \mathrm{e}, \mathrm{f}, \mathrm{g}}$ & 0.03 & $0 \cdot 6^{\mathrm{a}, \mathrm{b}, \mathrm{c}}$ & 0.01 & $0 \cdot 7^{b, g, h, i, j}$ & 0.02 & $0.8^{\mathrm{d}, \mathrm{h}, \mathrm{k}, \mathrm{m}, \mathrm{n}}$ & 0.03 & $0.9^{\mathrm{m}, \mathrm{o}}$ & 0.06 & $0 \cdot 8^{\mathrm{e}, \mathrm{i}, \mathrm{l}, \mathrm{n}, \mathrm{o}}$ & 0.05 & $0 \cdot 7^{\mathrm{c}, \mathrm{f}, \mathrm{j}, \mathrm{k}, \mathrm{l}}$ & 0.03 \\
\hline $\begin{array}{l}\text { Left ventricle + septum wet weight } \\
(\mathrm{mg} / \mathrm{mm})\end{array}$ & $19 \cdot 4^{\mathrm{a}, \mathrm{b}, \mathrm{c}}$ & 0.8 & $20 \cdot 8^{a, b, c}$ & 0.5 & $19 \cdot 3^{a, b, c}$ & 0.6 & $22 \cdot 5^{\mathrm{b}}$ & 1.5 & $22 \cdot 3^{\mathrm{b}}$ & $1 \cdot 3$ & $20 \cdot 7^{\mathrm{a}, \mathrm{b}, \mathrm{c}}$ & 0.8 & $17 \cdot 2^{c}$ & 0.7 \\
\hline $\begin{array}{l}\text { Right ventricle wet weight } \\
(\mathrm{mg} / \mathrm{mm})\end{array}$ & $3.7^{\mathrm{a}}$ & 0.5 & $4 \cdot 5^{\mathrm{a}}$ & 0.1 & $3 \cdot 7^{\mathrm{a}}$ & 0.2 & $3 \cdot 4^{\mathrm{a}}$ & 0.1 & $3.9^{\mathrm{a}}$ & 0.3 & $3 \cdot 6^{\mathrm{a}}$ & 0.2 & $3 \cdot 6^{\mathrm{a}}$ & 0.4 \\
\hline $\begin{array}{l}\text { Left ventricle fibrosis (\% surface } \\
\text { area) }\end{array}$ & $3 \cdot 3^{a}$ & 0.7 & $3.8^{\mathrm{a}}$ & 0.6 & $4 \cdot 1^{a}$ & 0.9 & $5 \cdot 6^{\mathrm{a}}$ & 0.4 & $7 \cdot 8$ & 0.6 & $4 \cdot 6^{\mathrm{a}}$ & 0.5 & $4 \cdot 2^{\mathrm{a}}$ & 0.7 \\
\hline Diastolic stiffness (к) & $20 \cdot 5^{\mathrm{a}, \mathrm{b}, \mathrm{c}}$ & 0.4 & $24 \cdot 6^{\mathrm{a}, \mathrm{d}, \mathrm{f}, \mathrm{h}, \mathrm{i}}$ & 0.8 & $20 \cdot 9^{\mathrm{b}, \mathrm{d}, \mathrm{e}}$ & $1 \cdot 2$ & $26 \cdot 3^{g, h, j}$ & $2 \cdot 2$ & $28 \cdot 7^{\mathrm{i}, \mathrm{j}, \mathrm{k}}$ & 0.8 & $30 \cdot 6^{\mathrm{k}}$ & $1 \cdot 1$ & $22 \cdot 4^{\mathrm{ce}, \mathrm{e}, \mathrm{f} g}$ & 1.3 \\
\hline Systolic blood pressure (mmHg) & $125 \cdot 1^{\mathrm{a}, \mathrm{e}, \mathrm{f}, \mathrm{g}}$ & $4 \cdot 3$ & $123 \cdot 9^{\mathrm{a}, \mathrm{b}, \mathrm{c}, \mathrm{d}}$ & 1.0 & $126 \cdot 8^{\mathrm{b}, \mathrm{e}, \mathrm{h}, \mathrm{i}}$ & $1 . \overline{3}$ & $137 \cdot 0^{k}$ & $1 \cdot 2$ & $145 \cdot 0$ & 4.5 & $129 \cdot 9^{\mathrm{c}, \mathrm{f}, \mathrm{h}, \mathrm{j}, \mathrm{k}}$ & 0.6 & $127 \cdot 3^{\mathrm{d}, \mathrm{g}, \mathrm{i}, \mathrm{j}}$ & $1 \cdot 1$ \\
\hline
\end{tabular}

M, maize starch diet; MC, maize starch + $\beta$-carotene diet; MP, maize starch + purple carrot juice diet; $\mathrm{H}$, high-carbohydrate, high-fat diet; HC, high-carbohydrate, high-fat + $\beta$-carotene diet; HP, high-carbohydrate, high-fat + purple carrot juice diet; LVIDd, left ventricular internal diameter in diastole; LVIDs, left ventricular internal diameter in systole; LVPWd, left ventricular posterior wall thickness in diastole; $\mathrm{E}_{\mathrm{M}}$, early mitral inflow velocity; $A_{M}$, late mitral inflow velocity; MCMO, mitral closing-mitral opening time.

${ }^{a-p}$ Mean values within a row with unlike superscript letters were significantly different $(P<0.05)$.

${ }^{\star}$ Four animals per group. 
(A)

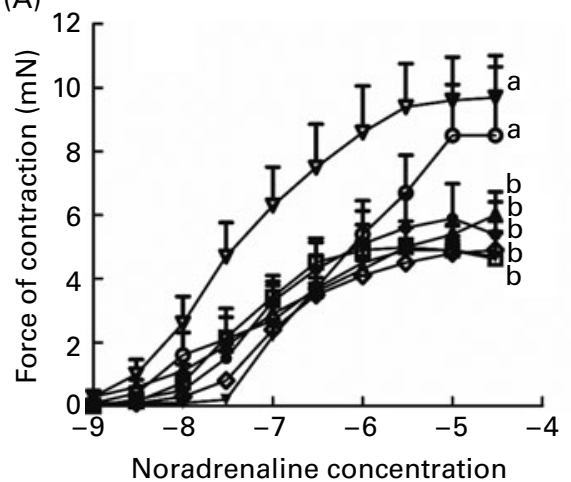

( $\log \mathrm{mol} / \mathrm{l}$ )
(B) Sodium nitroprusside concentration ( $\log \mathrm{mol} / \mathrm{l})$

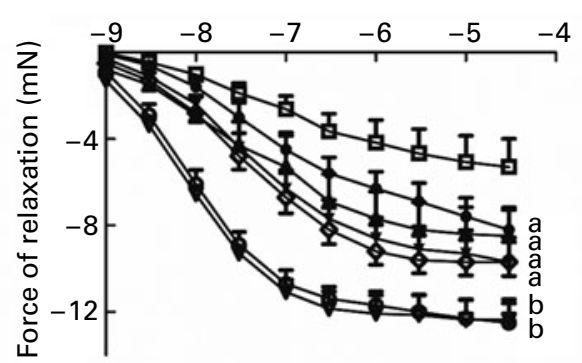

(C)

Acetylcholine concentration ( $\log \mathrm{mol} / \mathrm{l}$ )

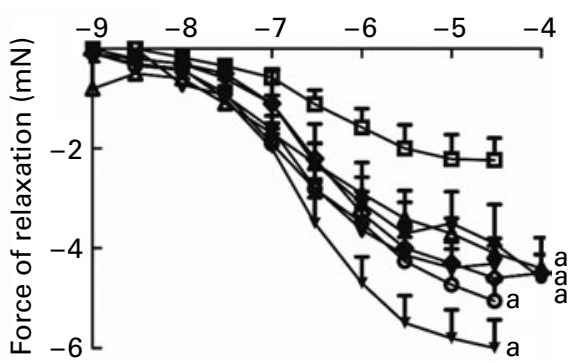

Fig. 1. Cumulative concentration-response curves for noradrenaline (A), sodium nitroprusside (B) and acetylcholine (C) in thoracic aortic rings from maize starch diet $(O)$, maize starch diet $+\beta$-carotene $(\triangle)$, maize starch diet + purple carrot juice $(\diamond)$, high-carbohydrate, high-fat diet for 8 weeks $(\nabla)$, high-carbohydrate, highfat diet for 16 weeks $(\square)$, high-carbohydrate, high-fat diet $+\beta$-carotene $(\bullet)$ and high-carbohydrate, high-fat diet + purple carrot juice $(\mathbf{\nabla})$-fed rats. Values are means for eight to ten rats per group, with standard errors represented by vertical bars. ${ }^{\mathrm{a}, \mathrm{b}}$ Mean values with an unlike letter were significantly different $(P<0 \cdot 05)$.

\section{Discussion}

A combination of high carbohydrate and high fat in the diet was used in the present study to mimic human diets that have been associated with the development of the metabolic syndrome. This diet produced changes in metabolic, cardiovascular and hepatic structure and functions such as excessive abdominal fat deposition, impaired glucose tolerance, elevated blood pressure and increased plasma lipid concentrations together with increased plasma oxidative stress markers and liver enzymes compared with maize starch diet-fed rats. Further, histological evaluation of heart and liver showed increased infiltration of inflammatory cells and increased collagen deposition in addition to increased fat vacuoles in the liver. This was accompanied by increased left ventricular stiffness and decreased aortic reactivity.

The present study compares therapeutic responses from anthocyanin-rich purple carrot juice with responses to $\beta$-carotene in high-carbohydrate, high-fat diet-fed rats. Since carotenoids are sparsely soluble in water, unlike anthocyanins, the purple carrot juice was very low in carotenoids but high in total anthocyanins. The present results suggest that many responses to purple carrot juice differ from those following $\beta$-carotene supplementation. $\beta$-Carotene and purple carrot juice produced different responses on blood lipid profiles, lipid deposition in the liver, plasma alkaline phosphatase and lactate dehydrogenase activities, left ventricular stiffness and plasma markers of oxidative stress such as uric acid and malondialdehyde. The responses to $\beta$-carotene may be produced by vitamin $\mathrm{A}$ and its major metabolites, retinoic acid and retinaldehyde. Rats fed with vitamin A and retinoic acid showed a marked increase in hepatic and plasma concentrations of glycogen, cholesterol and acylglycerols with elevated plasma NEFA and increased glucose incorporation into liver lipids ${ }^{(41,42)}$. Vitamin A stimulated fatty acid mobilisation from adipose tissue and enhanced formation of glycerophosphate through glycolysis, with consequent increases in the acylglycerol synthesis in the liver ${ }^{(41)}$. Additionally, both retinoic acid and retinaldehyde inhibited adipogenesis ${ }^{(43)}$. Here we show that $\beta$-carotene prevented further increases in abdominal fat weight after treatment. It is therefore likely that $\beta$-carotene and its major metabolites suppress adipogenesis, thereby allowing excess accumulation of lipids in the liver and the plasma.
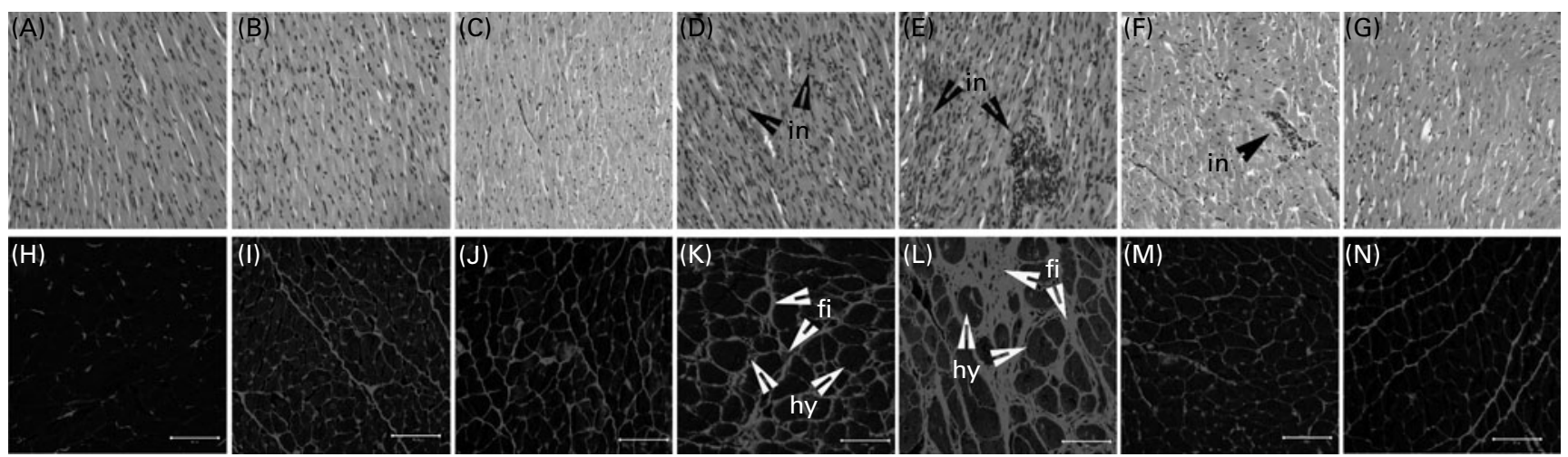

Fig. 2. Haematoxylin and eosin staining of left ventricle $(\times 20)$ showing inflammatory cells (marked as 'in') as dark spots outside the myocytes in maize starch diet $(A)$, maize starch diet $+\beta$-carotene $(B)$, maize starch diet + purple carrot juice $(C)$, high-carbohydrate, high-fat diet for 8 weeks (D), high-carbohydrate, high-fat diet for 16 weeks $(E)$, high-carbohydrate, high-fat diet $+\beta$-carotene $(F)$ and high-carbohydrate, high-fat diet + purple carrot juice $(G)$-fed rats. Picrosirius red staining of left ventricular interstitial collagen deposition $(40 \times)$ in maize starch diet $(\mathrm{H})$, maize starch diet $+\beta$-carotene $(\mathrm{I})$, maize starch diet + purple carrot juice $(\mathrm{J})$, high-carbohydrate, high-fat diet for 8 weeks $(\mathrm{K})$, high-carbohydrate, high-fat diet for 16 weeks $(\mathrm{L})$, high-carbohydrate, high-fat diet $+\beta$-carotene $(\mathrm{M})$ and high-carbohydrate, high-fat diet + purple carrot juice $(\mathrm{N})$-fed rats; fibrosis is marked as 'fi' and hypertrophied cardiomyocytes are marked as 'hy'. 

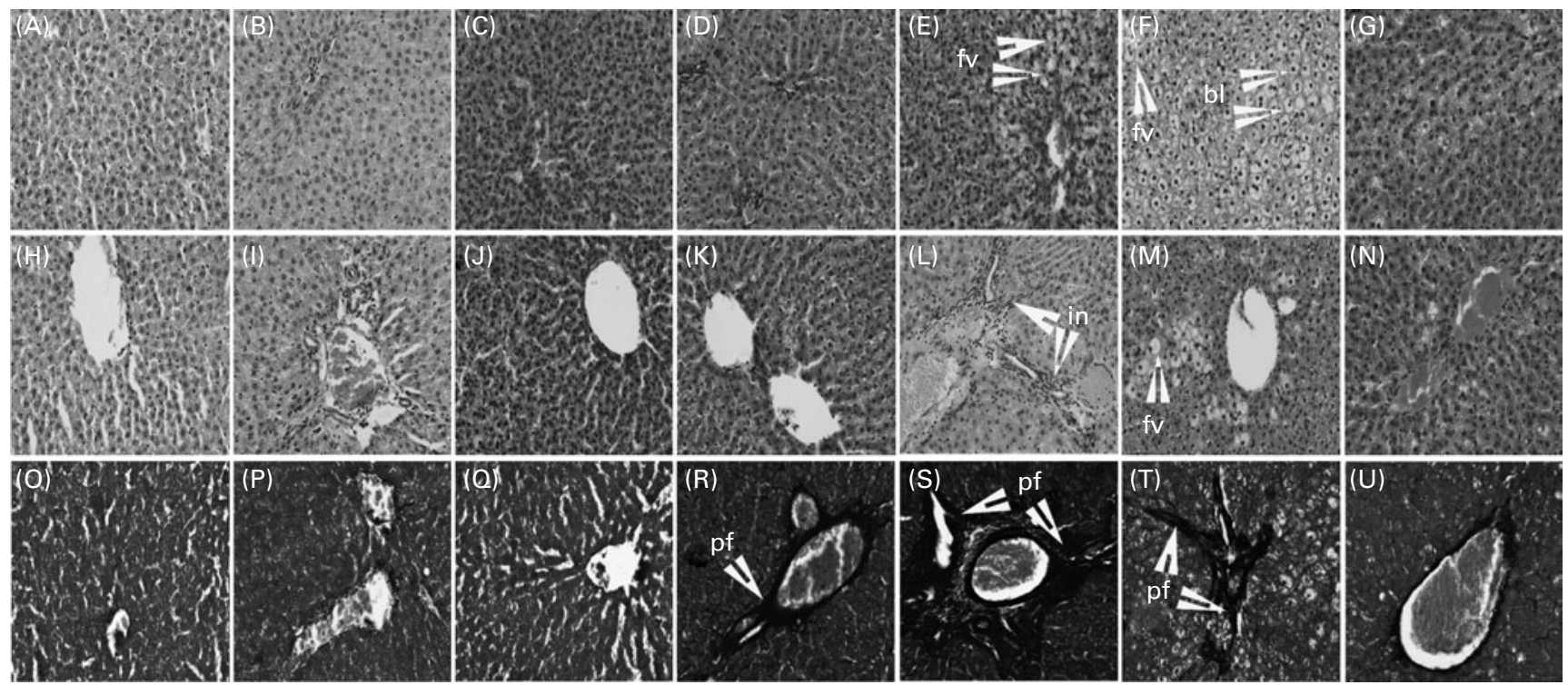

Fig. 3. Haematoxylin and eosin staining of hepatocytes $(\times 40)$ showing hepatocytes with enlarged fat vacuoles (marked as 'fv') and inflammatory cells (marked as 'in') $(20 \times)$ from maize starch diet $(A, H)$, maize starch diet $+\beta$-carotene $(B, I)$, maize starch diet + purple carrot juice $(C$, J), high-carbohydrate, high-fat diet for 8 weeks $(D, K)$, high-carbohydrate, high-fat diet for 16 weeks $(E, L)$, high-carbohydrate, high-fat diet $+\beta$-carotene $(F, M)$ and high-carbohydrate, high-fat diet + purple carrot juice $(\mathrm{G}, \mathrm{N})$-fed rats. Milligan's trichrome staining of the hepatic portal regions showing collagen (marked as 'pf') (20 $\times)$ in maize starch diet $(\mathrm{O})$, maize starch diet $+\beta$-carotene $(P)$, maize starch diet + purple carrot juice $(Q)$, high-carbohydrate, high-fat diet for 8 weeks $(R)$, high-carbohydrate, high-fat diet for 16 weeks $(S)$, high-carbohydrate, high-fat diet $+\beta$-carotene $(T)$ and high-carbohydrate, high-fat diet + purple carrot juice (U)-fed rats. bl, Hepatocyte ballooning.

In the heart, retinoic acid inhibited G protein-coupled receptor-mediated hypertrophy as well as angiotensin II-induced increases in intracellular $\mathrm{Ca}^{2+}$ in neonatal cardiomyocytes ${ }^{(44)}$. In vivo, retinoic acid suppressed myocardial cell hypertrophy ${ }^{(44)}$ and prevented ventricular fibrosis and remodelling in spontaneously hypertensive rats ${ }^{(45)}$. $\beta$-Carotene and carotenoid breakdown products induced apoptosis in Jurkat E6.1 malignant T-lymphoblast cells ${ }^{(46)}$ and human neutrophils ${ }^{(47)}$ but impaired mitochondrial respiration and elevated accumulation of malondialdehyde ${ }^{(48)}$. Thus, $\beta$-carotene as a precursor of vitamin A and retinoic acid may increase lipid peroxidation, decrease cardiac hypertrophy, and prevent cardiac fibrosis and inflammation.

In contrast, purple carrot juice supplementation normalised plasma TAG, total cholesterol and NEFA concentrations, consistent with the hypolipidaemic responses to other anthocyanin-rich plant extracts such as blueberry leaf ${ }^{(29)}$. NEFA is involved both in insulin resistance and hypertension by inhibiting aortic endothelial NO synthase activity through an oxidative mechanism ${ }^{(49,50)}$. The present results demonstrated enhanced vascular relaxant responses, consistent with improved NO production and lowered blood pressure.

Table 4. Changes in hepatic structure and function

(Mean values with their standard errors for ten animals per group)

\begin{tabular}{|c|c|c|c|c|c|c|c|c|c|c|c|c|c|c|}
\hline \multirow[b]{2}{*}{ Parameter } & \multicolumn{2}{|l|}{ M } & \multicolumn{2}{|l|}{ MC } & \multicolumn{2}{|l|}{ MP } & \multicolumn{2}{|c|}{ H (8 weeks) } & \multicolumn{2}{|c|}{ H (16 weeks) } & \multicolumn{2}{|l|}{$\mathrm{HC}$} & \multicolumn{2}{|l|}{$\mathrm{HP}$} \\
\hline & Mean & SEM & Mean & SEM & Mean & SEM & Mean & SEM & Mean & SEM & Mean & SEM & Mean & SEM \\
\hline $\begin{array}{l}\text { Liver wet } \\
\quad \text { weight } \\
(\mathrm{mg} / \mathrm{mm})\end{array}$ & $303 \cdot 3^{\mathrm{b}, \mathrm{g}, \mathrm{i}}$ & $9 \cdot 8$ & $222 \cdot 1^{\mathrm{a}}$ & $7 \cdot 0$ & $231 \cdot 2^{\mathrm{a}}$ & $13 \cdot 0$ & $302 \cdot 8^{\mathrm{c}, \mathrm{f}, \mathrm{h}, \mathrm{i}}$ & $12 \cdot 9$ & $328.5^{\mathrm{e}, \mathrm{h}}$ & $10 \cdot 0$ & $297 \cdot 0^{\mathrm{d}, \mathrm{e}, \mathrm{f}, \mathrm{g}}$ & 8.9 & $273 \cdot 7^{\mathrm{b}, \mathrm{c}, \mathrm{d}}$ & 13.0 \\
\hline $\begin{array}{l}\text { Liver fibrosis } \\
\quad(\% \text { surface } \\
\text { area }{ }^{*}\end{array}$ & $0.9^{a, b, c, d}$ & 0.02 & $1 \cdot 1^{\mathrm{a}, \mathrm{e}, \mathrm{h}, \mathrm{i}}$ & 0.1 & $1 \cdot 0^{\mathrm{b}, \mathrm{e}, \mathrm{f}, \mathrm{g}}$ & 0.1 & $3 \cdot 6^{\mathrm{k}}$ & 0.8 & $5 \cdot 7$ & 0.5 & $2 \cdot 4^{\mathrm{c}, \mathrm{f}, \mathrm{h}, \mathrm{j}, \mathrm{k}}$ & 0.3 & $1 \cdot 8^{\mathrm{d}, \mathrm{g}, \mathrm{i}, \mathrm{j}}$ & 0.7 \\
\hline $\operatorname{ALT}(\mathrm{U} / \mathrm{I})$ & $32 \cdot 9^{\mathrm{d}, \mathrm{g}, \mathrm{h}, \mathrm{i}}$ & $2 \cdot 0$ & $59 \cdot 8^{k}$ & $7 \cdot 0$ & $31 \cdot 0^{\mathrm{a}, \mathrm{b}, \mathrm{c}, \mathrm{d}}$ & 1.9 & $36 \cdot 1^{\mathrm{c}, \mathrm{f}, \mathrm{h}, \mathrm{j}}$ & $2 \cdot 2$ & $55 \cdot 3^{k}$ & $3 \cdot 7$ & $31 \cdot 0^{\mathrm{a}, \mathrm{e}, \mathrm{f}, \mathrm{g}}$ & $3 \cdot 6$ & $41 \cdot 2^{\mathrm{b}, \mathrm{e}, \mathrm{i}, \mathrm{j}}$ & 3.4 \\
\hline AST (U/I) & $71 \cdot 0^{\mathrm{a}, \mathrm{h}, \mathrm{g}, \mathrm{i}}$ & $4 \cdot 0$ & $118 \cdot 1^{\mathrm{k}}$ & $14 \cdot 2$ & $70 \cdot 8^{\mathrm{a}, \mathrm{b}, \mathrm{c}, \mathrm{d}}$ & $5 \cdot 1$ & $77^{\mathrm{b}, \mathrm{f}, \mathrm{i}, \mathrm{j}, \mathrm{k}}$ & 2.5 & 101.7 & $5 \cdot 4$ & $65 \cdot 2^{\mathrm{c}, \mathrm{e}, \mathrm{f}, \mathrm{h}}$ & 3.0 & $75 \cdot 3^{d, e, g, j}$ & 3.8 \\
\hline ALP (U/I) & $154 \cdot 7^{\mathrm{a}, \mathrm{d}, \mathrm{e}}$ & $2 \cdot 0$ & $167 \cdot 6^{\mathrm{c}, \mathrm{e}}$ & 6.5 & $133 \cdot 6^{a, b}$ & $7 \cdot 1$ & $192 \cdot 4^{f}$ & $5 \cdot 2$ & $208 \cdot 4^{f, g}$ & 0.6 & $224 \cdot 8^{g}$ & $14 \cdot 3$ & $153 \cdot 5^{\mathrm{b}, \mathrm{c}, \mathrm{d}}$ & $6 \cdot 2$ \\
\hline Albumin $(g / l)$ & $28 \cdot 5^{a, b}$ & 0.6 & $27 \cdot 7^{\mathrm{a}}$ & 0.4 & $29 \cdot 1^{a, b}$ & 0.6 & $28.0^{\mathrm{a}}$ & 0.6 & $28 \cdot 0^{\mathrm{a}}$ & 0.2 & $27 \cdot 4^{\mathrm{a}}$ & 0.2 & $29 \cdot 9^{b}$ & 0.5 \\
\hline Globulin (g/l) & $29 \cdot 6^{a, b}$ & 1.0 & $26 \cdot 2^{\mathrm{b}}$ & 0.8 & $29 \cdot 4^{a, b}$ & 0.8 & $28 \cdot 2^{a, b}$ & 0.8 & $28 \cdot 7^{\mathrm{a}, \mathrm{b}}$ & 0.7 & $27 \cdot 6^{a, b}$ & 0.7 & $29 \cdot 9^{\mathrm{a}}$ & 1.0 \\
\hline $\begin{array}{l}\text { Total bilirubin } \\
(\mu \mathrm{mol} / \mathrm{l})\end{array}$ & $2 \cdot 2^{a, b}$ & 0.1 & $3 \cdot 0^{a}$ & 0.6 & $1.5^{\mathrm{b}}$ & 0.07 & $2 \cdot 2^{a, b}$ & 0.07 & $2 \cdot 3^{a, b}$ & 0.05 & $2 \cdot 1^{a, b}$ & 0.2 & $2 \cdot 1^{a, b}$ & 0.1 \\
\hline
\end{tabular}

M, maize starch diet; MC, maize starch + $\beta$-carotene diet; MP, maize starch + purple carrot juice diet; $\mathrm{H}$, high-carbohydrate, high-fat diet; HC, high-carbohydrate, high-fat $+\beta$ carotene diet; HP, high-carbohydrate, high-fat + purple carrot juice diet; ALT, alanine transaminase; AST, aspartate transaminase; ALP, alkaline phosphatase.

${ }^{a-k}$ Mean values within a row with unlike superscript letters were significantly different $(P<0.05)$.

${ }^{\star}$ Four animals per group. 
Left ventricular dysfunction has been correlated with metabolic disturbances, oxidative stress and the appearance of inflammatory cells preceding left ventricular fibrosis and left ventricular stiffness ${ }^{(51)}$. Purple carrot juice supplementation reduced left ventricular stiffness, the number of inflammatory cells and left ventricular collagen deposition. Echocardiographic assessment showed improved systolic function and decreased left ventricular dimensions following purple carrot treatment. Along with other results, reduction in lactate dehydrogenase activity and improved $\mathrm{N}$ homeostasis with purple carrot juice supplementation could be indicative of normalised metabolism leading to cardioprotective effects. Our data also showed that uric acid concentrations decreased in the purple carrot juice-treated rats. Uric acid, the endproduct of purine metabolism and a major endogenous water-soluble antioxidant ${ }^{(52)}$, is increased in fructose-fed rats following increased production of reactive oxygen species ${ }^{(33)}$. Additionally, the reduction in plasma malondialdehyde concentrations, a major product of PUFA peroxidation, suggests in vivo antioxidant activity of purple carrot juice.

In contrast to $\beta$-carotene, purple carrot juice supplementation reduced liver wet weight, portal inflammation, fat deposition and portal fibrosis in the liver and showed total restoration of liver function. We have shown that purple carrot juice reversed the pathological features of NAFLD in the high-carbohydrate, high-fat diet-fed rats. Increased activities of the serum enzymes including aspartate transaminase, alanine transaminase and alkaline phosphatase reflect active liver damage. Inflammatory hepatocellular disorders result in extremely elevated transaminase levels ${ }^{(53)}$. Thus, purple carrot juice treatment has a significant role in the decrease or reversal of liver dysfunction since the activity of these plasma enzymes was lower than in high-carbohydratehigh-fat diet-fed rats and similar to maize starch diet-fed rats. Both $\beta$-carotene and purple carrot juice reduced plasma CRP concentrations, suggesting their possible in vivo anti-inflammatory effects.

The present study demonstrates for the first time that treatment of the metabolic syndrome induced by diet in rats with purple carrot juice attenuates or reverses the changes in cardiovascular and liver structure and functions as well as in metabolic parameters, especially abdominal fat deposition and plasma lipid profiles. As the juice itself contained low concentrations of carotenoids, it is likely that the anthocyanins are responsible for the antioxidant and anti-inflammatory properties of purple carrot juice. Furthermore, $\beta$-carotene alone produces limited and sometimes contradictory responses compared with purple carrot juice in this rat model of the metabolic syndrome.

\section{Acknowledgements}

We thank Mr Greg Jardine (Dr Red Nutraceuticals, Mt Nebo, QLD, Australia) for financial support to allow this project to be undertaken. The purple carrot juice was supplied by SDS Beverages Pty Ltd (Irymple, VIC, Australia). We thank Dr Fiona Campbell, School of Veterinary Science, The University of Queensland, for the acquisition of echocardiographic images.

H. P. and L. B. developed the original study aims; H. P. and S. P. conducted the experiments and carried out the data analyses; data were interpreted by all authors. The preparation of the manuscript drafts has involved all authors and L. B. has been the corresponding author throughout the writing process.

There are no conflicts of interest.

\section{References}

1. O'Keefe JH, Gheewala NM \& O'Keefe JO (2008) Dietary strategies for improving post-prandial glucose, lipids, inflammation, and cardiovascular health. $J$ Am Coll Cardiol 51, 249-255.

2. Bazzano LA, He J, Ogden LG, et al. (2002) Fruit and vegetable intake and risk of cardiovascular disease in US adults: the first National Health and Nutrition Examination Survey Epidemiologic Follow-up Study. Am J Clin Nutr 76, 93-99.

3. Joshipura KJ, Ascherio A, Manson JE, et al. (1999) Fruit and vegetable intake in relation to risk of ischemic stroke. JAMA 282, 1233-1239.

4. Joshipura KJ, Hu FB, Manson JE, et al. (2001) The effect of fruit and vegetable intake on risk for coronary heart disease. Ann Intern Med 134, 1106-1114.

5. Appel LJ, Moore TJ, Obarzanek E, et al. (1997) A clinical trial of the effects of dietary patterns on blood pressure. DASH Collaborative Research Group. $N$ Engl J Med 336, 1117-1124.

6. Hamer M \& Chida Y (2007) Intake of fruit, vegetables, and antioxidants and risk of type 2 diabetes: systematic review and meta-analysis. J Hypertens 25, 2361-2369.

7. Dembinska-Kiec A, Mykkanen O, Kiec-Wilk B, et al. (2008) Antioxidant phytochemicals against type 2 diabetes. $\mathrm{Br} J$ Nutr 99, E Suppl. 1, ES109-ES117.

8. Marchesini G, Brizi M, Bianchi G, et al. (2001) Nonalcoholic fatty liver disease: a feature of the metabolic syndrome. Diabetes 50, 1844-1850.

9. van Dokkum W, Frølich W, Saltmarsh M, et al. (2008) The health effects of bioactive plant components in food: results and opinions of the EU COST 926 action. Nutr Bull 33, 133-139.

10. Scalbert A \& Williamson G (2000) Dietary intake and bioavailability of polyphenols. J Nutr 130, 2073S-2085S.

11. Moore T (1929) Vitamin A and carotene: the association of vitamin A activity with carotene in the carrot root. Biochem $J$ 23, 803-811.

12. Metzger BT, Barnes DM \& Reed JD (2008) Purple carrot (Daucus carota L.) polyacetylenes decrease lipopolysaccharide-induced expression of inflammatory proteins in macrophage and endothelial cells. J Agric Food Chem 56, 3554-3560.

13. Sun T, Simon PW \& Tanumihardjo SA (2009) Antioxidant phytochemicals and antioxidant capacity of biofortified carrots (Daucus carota L.) of various colors. J Agric Food Chem 57, 4142-4147.

14. Grassmann J, Schnitzler WH \& Habegger R (2007) Evaluation of different coloured carrot cultivars on antioxidative capacity based on their carotenoid and phenolic contents. Int J Food Sci Nutr 58, 603-611.

15. Charron CS, Kurilich AC, Clevidence BA, et al. (2009) Bioavailability of anthocyanins from purple carrot juice: effects of acylation and plant matrix. J Agric Food Chem 57, 1226-1230.

16. Christensen LP \& Kreutzmann S (2007) Determination of polyacetylenes in carrot roots (Daucus carota L.) by highperformance liquid chromatography coupled with diode array detection. J Sep Sci 30, 483-490.

17. Hozawa A, Jacobs DR Jr, Steffes MW, et al. (2009) Circulating carotenoid concentrations and incident hypertension: the Coronary Artery Risk Development in Young Adults (CARDIA) study. J Hypertens 27, 237-242. 
18. Yanagisawa A, Suzuki K, Kimura A, et al. (2009) Possible protective effect of serum $\beta$-carotene levels on the association between interleukin-1B C-31T polymorphism and hypertension in a Japanese population. Clin Nutr 28, 198-202.

19. Liu S, Ajani U, Chae C, et al. (1999) Long-term $\beta$-carotene supplementation and risk of type 2 diabetes mellitus: a randomized controlled trial. JAMA 282, 1073-1075.

20. Kataja-Tuomola M, Sundell JR, Mannisto S, et al. (2008) Effect of $\alpha$-tocopherol and $\beta$-carotene supplementation on the incidence of type 2 diabetes. Diabetologia 51, 47-53.

21. Paiva SA \& Russell RM (1999) $\beta$-Carotene and other carotenoids as antioxidants. $J$ Am Coll Nutr 18, 426-433.

22. El-Agamey A, Lowe GM, McGarvey DJ, et al. (2004) Carotenoid radical chemistry and antioxidant/pro-oxidant properties. Arch Biochem Biophys 430, 37-48.

23. Tapiero H, Townsend DM \& Tew KD (2004) The role of carotenoids in the prevention of human pathologies. Biomed Pharmacother 58, 100-110.

24. Lin WT, Huang CC, Lin TJ, et al. (2009) Effects of $\beta$-carotene on antioxidant status in rats with chronic alcohol consumption. Cell Biochem Funct 27, 344-350.

25. Maritim A, Dene BA, Sanders RA, et al. (2002) Effects of $\beta$-carotene on oxidative stress in normal and diabetic rats. J Biochem Mol Toxicol 16, 203-208.

26. Furusho T, Kataoka E, Yasuhara T, et al. (2002) Administration of $\beta$-carotene suppresses lipid peroxidation in tissues and improves the glucose tolerance ability of streptozotocin-induced diabetic rats. Int J Vitam Nutr Res 72, 71-76.

27. Kris-Etherton PM, Hecker KD, Bonanome A, et al. (2002) Bioactive compounds in foods: their role in the prevention of cardiovascular disease and cancer. Am J Med 113, Suppl. 9B, $71 \mathrm{~S}-88 \mathrm{~S}$.

28. Galvano F, La Fauci L, Lazzarino G, et al. (2004) Cyanidins: metabolism and biological properties. J Nutr Biochem 15, 2-11.

29. Cignarella A, Nastasi M, Cavalli E, et al. (1996) Novel lipid-lowering properties of Vaccinium myrtillus L. leaves, a traditional antidiabetic treatment, in several models of rat dyslipidaemia: a comparison with ciprofibrate. Thromb Res 84, 311-322.

30. Valcheva-Kuzmanova S, Kuzmanov K, Mihova V, et al. (2007) Antihyperlipidemic effect of Aronia melanocarpa fruit juice in rats fed a high-cholesterol diet. Plant Foods Hum Nutr 62, $19-24$.

31. Guo H, Ling W, Wang Q, et al. (2007) Effect of anthocyaninrich extract from black rice (Oryza sativa L. indica) on hyperlipidemia and insulin resistance in fructose-fed rats. Plant Foods Hum Nutr 62, 1-6.

32. Shindo M, Kasai T, Abe A, et al. (2007) Effects of dietary administration of plant-derived anthocyanin-rich colors to spontaneously hypertensive rats. J Nutr Sci Vitaminol (Tokyo) 53, 90-93.

33. Stanhope KL \& Havel PJ (2008) Fructose consumption: potential mechanisms for its effects to increase visceral adiposity and induce dyslipidemia and insulin resistance. Curr Opin Lipidol 19, 16-24.

34. Buettner R, Scholmerich J \& Bollheimer LC (2007) High-fat diets: modeling the metabolic disorders of human obesity in rodents. Obesity (Silver Spring) 15, 798-808.

35. Poudyal H, Campbell F \& Brown L (2010) Olive leaf extract attenuates cardiac, hepatic, and metabolic changes in high carbohydrate-, high fat-fed rats. J Nutr 140, 946-953.
36. Zhang G \& Hamaker BR (2009) Slowly digestible starch: concept, mechanism, and proposed extended glycemic index. Crit Rev Food Sci Nutr 49, 852-867.

37. Lee J, Durst RW \& Wrolstad RE (2005) Determination of total monomeric anthocyanin pigment content of fruit juices, beverages, natural colorants, and wines by the $\mathrm{pH}$ differential method: collaborative study. J AOAC Int 88, 1269-1278.

38. Brown L, Fenning A, Chan V, et al. (2002) Echocardiographic assessment of cardiac structure and function in rats. Heart Lung Circ 11, 167-173.

39. Brown L, Duce B, Miric G, et al. (1999) Reversal of cardiac fibrosis in deoxycorticosterone acetate-salt hypertensive rats by inhibition of the renin-angiotensin system. J Am Soc Nephrol 10, Suppl. 11, S143-S148.

40. Sim AS, Salonikas C, Naidoo D, et al. (2003) Improved method for plasma malondialdehyde measurement by high-performance liquid chromatography using methyl malondialdehyde as an internal standard. J Chromatogr B Analyt Technol Biomed Life Sci 785, 337-344.

41. Singh VN, Singh M \& Venkitasubramanian TA (1969) Early effects of feeding excess vitamin A: mechanism of fatty liver production in rats. $J$ Lipid Res 10, 395-401.

42. Gerber LE \& Erdman JW Jr (1979) Effect of retinoic acid and retinyl acetate feeding upon lipid metabolism in adrenalectomized rats. J Nutr 109, 580-589.

43. Ziouzenkova O, Orasanu G, Sharlach M, et al. (2007) Retinaldehyde represses adipogenesis and diet-induced obesity. Nat Med 13, 695-702.

44. Pan J \& Baker KM (2007) Retinoic acid and the heart. Vitam Horm 75, 257-283.

45. Lu L, Yao T, Zhu YZ, et al. (2003) Chronic all-trans retinoic acid treatment prevents medial thickening of intramyocardial and intrarenal arteries in spontaneously hypertensive rats. Am J Physiol Heart Circ Physiol 285, H1370-H1377.

46. Muller K, Carpenter KL, Challis IR, et al. (2002) Carotenoids induce apoptosis in the T-lymphoblast cell line Jurkat E6.1. Free Radic Res 36, 791-802.

47. Siems W, Capuozzo E, Crifo C, et al. (2003) Carotenoid cleavage products modify respiratory burst and induce apoptosis of human neutrophils. Biochim Biophys Acta 1639, 27-33.

48. Siems W, Sommerburg O, Schild L, et al. (2002) $\beta$-Carotene cleavage products induce oxidative stress in vitro by impairing mitochondrial respiration. FASEB J 16, 1289-1291.

49. Du X, Edelstein D, Obici S, et al. (2006) Insulin resistance reduces arterial prostacyclin synthase and eNOS activities by increasing endothelial fatty acid oxidation. J Clin Invest 116, $1071-1080$

50. Steinberg HO, Tarshoby M, Monestel R, et al. (1997) Elevated circulating free fatty acid levels impair endothelium-dependent vasodilation. J Clin Invest 100, 1230-1239.

51. van Heerebeek L, Somsen A \& Paulus WJ (2009) The failing diabetic heart: focus on diastolic left ventricular dysfunction. Curr Diab Rep 9, 79-86.

52. Mene P \& Punzo G (2008) Uric acid: bystander or culprit in hypertension and progressive renal disease? J Hypertens $\mathbf{2 6}$, 2085-2092.

53. Hultcrantz R, Mengarelli S \& Strandvik B (1986) Morphological findings in the liver of children with cystic fibrosis: a light and electron microscopical study. Hepatology 6, 881-889.

54. Hubbell RB, Mendel LB \& Wakeman AJ (1937) New salt mixture for use in experimental diets. J Nutr 14, 273-285. 